\title{
Nonsteroidal Anti-Inflammatory Drugs and Ectodomain Shedding of the Amyloid Precursor Protein
}

\author{
Stefanie Leuchtenberger ${ }^{a} \quad J$ uan Maler ${ }^{b}$ Eva Czirr $^{a} \quad$ Julia Ness ${ }^{a}$ \\ Stefan F. Lichtenthaler ${ }^{d}$ Hermann Esselmann ${ }^{b}$ Claus U. Pietrzik ${ }^{c}$ \\ Jens Wiltfang ${ }^{b}$ Sascha Weggen ${ }^{a}$ \\ ${ }^{a}$ Molecular Neuropathology Group, Department of Neuropathology, Heinrich Heine University, Düsseldorf, \\ ${ }^{\mathrm{b}}$ Molecular Neurobiology Laboratory, Department of Psychiatry and Psychotherapy, University of \\ Erlangen-Nürnberg, Erlangen, ' Molecular Neurodegeneration Group, Institute of Physiological Chemistry \\ and Pathobiochemistry, Johannes Gutenberg University Mainz, Mainz, and ${ }^{\mathrm{d}}$ Adolf Butenandt Institute, \\ Ludwig Maximilians University München, München, Germany
}

\section{Key Words}

Alzheimer's disease $\cdot$ Nonsteroidal anti-inflammatory drugs - Ibuprofen - Indomethacin - Amyloid precursor protein $\cdot$ Ectodomain shedding

\begin{abstract}
Background: Epidemiological studies have suggested that long-term use of nonsteroidal anti-inflammatory drugs (NSAIDs) is associated with a reduced incidence of Alzheimer's disease (AD). Several mechanisms have been proposed to explain these findings including increased shedding of the soluble ectodomain of the amyloid precursor protein (sAPP), which functions as a neurotrophic and neuroprotective factor in vitro and in vivo. Objective: To clarify whether NSAIDs consistently stimulate SAPP secretion. Methods: 293-EBNA cells with stable overexpression of an APP-alkaline phosphatase fusion protein (APP-AP), SH-SY5Y and PC12 cells or primary telencephalic chicken neurons were treated with ibuprofen or indomethacin. APP shedding was then determined by measuring AP activity in conditioned media, Western blot analysis with antibodies against total SAPP or specific for SAPP- $\alpha$, or in a pulse-chase paradigm. Results:
\end{abstract}

AP activity in conditioned media was not increased after NSAID treatment of 293-EBNA cells whereas it was elevated by phorbol ester. Surprisingly, ibuprofen or indomethacin treatment of SH-SY5Y and PC12 cells expressing endogenous APP did not cause changes in SAPP or SAPP- $\alpha$ secretion or downregulation of cellular APP. These findings were further corroborated in primary chicken neuronal cultures. Conclusions: Using various experimental settings, we were unable to confirm SAPP or SAPP- $\alpha$ stimulation with the NSAIDs ibuprofen and indomethacin in transfected and nontransfected cells of neuronal and nonneuronal origin. Importantly, these findings seem to rule out chronic SAPP stimulation as an alternative mechanism of NSAID action in AD.

Copyright $\odot 2008$ S. Karger AG, Basel

\section{Introduction}

Numerous epidemiological studies have supported the conclusion that chronic intake of nonsteroidal antiinflammatory drugs (NSAIDs) is associated with a lower risk of Alzheimer's disease (AD) [1]. However, the mech-

\section{KARGER}

Fax +4161306 1234

E-Mail karger@karger.ch

www.karger.com
(C) 2008 S. Karger AG, Basel

$1660-2854 / 09 / 0062-0001 \$ 26.00 / 0$

Accessible online at:

www.karger.com/ndd
Sascha Weggen

Department of Neuropathology, Heinrich Heine University

Moorenstrasse 5

DE-40225 Düsseldorf (Germany)

Tel. +4921181 04506, Fax +4921181 04577,E-Mail sweggen@uni-duesseldorf.de 
anism of action of these drugs remains unclear, and various activities that are either related to the anti-inflammatory properties of these compounds or are supposed to directly target amyloid precursor protein (APP) processing, amyloid- $\beta 42(\mathrm{~A} \beta 42)$ production and $A \beta$ aggregation could account for the protective effects of NSAIDs in $\mathrm{AD}$ [2].

Processing of the APP by $\alpha$ - or $\beta$-secretase generates large soluble amino-terminal ectodomains, sAPP- $\alpha$ and sAPP- $\beta$, and corresponding membrane-bound C-terminal fragments (APP-CTFs) [3]. sAPP has been shown to function as a paracrine neurotrophic and neuroprotective factor in vitro and in vivo. Biological activities of sAPP include promotion of neuronal cell survival, neurite outgrowth, synaptogenesis and synaptic plasticity [4]. Activation of various signal transduction pathways modulates sAPP release and the largely predominant APP cleavage by $\alpha$-secretase. For example, stimulation of muscarinic/metabotropic receptors enhances sAPP- $\alpha$ secretion through a protein kinase $\mathrm{C}$ (PKC)-dependent signaling pathway, and activation of $\mathrm{PKC}$ with phorbol esters stimulates SAPP- $\alpha$ secretion by itself $[5,6]$.

The high-affinity targets of NSAIDs, cyclooxygenases (COX), are the central enzymes in prostaglandin synthesis and oxidize arachidonic acid from membrane-bound phospholipids to prostaglandins [7]. Inhibition of COX by NSAIDs results in an intracellular buildup of arachidonic acid [8], and arachidonic acid and its metabolites can stimulate PKC activity [9]. It is therefore plausible that inhibition of COX by NSAIDs could lead to increased levels of arachidonic acid metabolites, activation of PKC, and subsequent stimulation of sAPP- $\alpha$ secretion. In this respect, it has been suggested that sustained treatment $(20 \mathrm{~h})$ with nanomolar to low micromolar concentrations $(0.1-10 \mu \mathrm{M})$ of the NSAIDs ibuprofen and indomethacin can prominently stimulate secretion of sAPP- $\alpha$ from endogenous APP in permanent neuronal cell lines [10]. This partially concurred with earlier results that indomethacin $(25-50 \mu \mathrm{M})$ stimulated sAPP secretion from a human glioblastoma cell line [11], and findings that short-term treatment $(30 \mathrm{~min})$ with indomethacin $(10$ $\mu \mathrm{M})$ acutely elevated sAPP- $\alpha$ release from neuronal cells [12]. However, several studies with APP-transfected cell lines failed to observe modulation of SAPP or SAPP- $\alpha$ release with ibuprofen or other NSAIDs [13-15]. Furthermore, increased levels of arachidonic acid resulted in stimulation of sAPP release from endogenous APP in PC12 cells and human platelets, but concomitant COX inhibition with indomethacin did not potentiate, but partially reversed this stimulation $[16,17]$.
Clarification of the mechanism of action of NSAIDs in $\mathrm{AD}$ is a high priority, particularly in regard to ongoing drug development efforts that aim for pharmacological optimization of individual NSAID activities [2]. Persistent stimulation of the neurotrophic/neuroprotective sAPP ectodomain by NSAIDs could provide yet another explanation for the protective effects of NSAIDs in AD. We therefore attempted to clarify whether NSAIDs are capable of modulating APP shedding and sAPP release using a variety of methods to accurately quantify sAPP levels. Surprisingly, we were unable to confirm sAPP stimulation by the widely used NSAIDs ibuprofen and indomethacin in permanent cell lines and primary neuronal cultures. Importantly, these findings seem to exclude chronic enhancement of APP ectodomain shedding as an alternative mechanism of NSAID action in AD.

\section{Materials and Methods}

\section{Drugs and Antibodies}

The NSAIDs ibuprofen and indomethacin were purchased from Biomol (Plymouth Meeting, Pa., USA), and phorbol-12-myristate-13-acetate (PMA) was obtained from Axxora (San Diego, Calif., USA). All other chemicals were from Sigma-Aldrich (Munich, Germany) except when otherwise indicated. Monoclonal antibodies (MAbs) IG7/5A3 raised against nonoverlapping epitopes in the APP ectodomain between amino acid residues $380-$ 665 , and polyclonal antiserum 863 raised against the mid-region of APP detect both sAPP- $\alpha$ and sAPP- $\beta[15,18]$. MAb 26 D6 against amino acid residues $1-12$ of the $A \beta$ sequence detects only sAPP- $\alpha$ [15]. Polyclonal antibody CT-15 was raised against the Cterminal 15 amino acid residues of human APP [15].

\section{Cell Lines, Preparation of Telencephalic Chicken Neurons,} and Drug Treatments

Rat pheochromocytoma PC12 cells, SH-SY5Y human neuroblastoma cells, and HEK 293-EBNA cells that stably express a fusion protein consisting of secretory alkaline phosphatase (AP) and full-length APP [19] were maintained in DMEM supplemented with $10 \%$ fetal bovine serum (FBS), $2 \mathrm{mM} \mathrm{L}$-glutamine, $2 \mathrm{mM}$ sodium pyruvat and $100 \mathrm{U} / \mathrm{ml}$ penicillin/streptomycin (Invitrogen, Carlsbad, Calif., USA). Fertilized chicken eggs were obtained from Charles River Laboratories (Wilmington, Mass., USA). Telencephalic cortices were dissected from 8-day-old chicken embryos, and neurons were prepared and cultured according to previously described procedures [20]. Experiments were carried out after 5 days of cultivation in neurobasal medium supplemented with B27 supplement, $2 \mathrm{mM}$ L-glutamine and $100 \mathrm{U} / \mathrm{ml}$ penicillin/streptomycin (Invitrogen). At least $24 \mathrm{~h}$ before drug treatments, permanent cell lines were transferred to serum-reduced medium ( $0.5 \%$ FBS). Cells were then treated for $24 \mathrm{~h}$ with increasing concentrations of NSAIDs, PMA or DMSO vehicle. Primary chicken neurons were treated in an analogous fashion in serumfree neurobasal medium. All treatments were carried out in duplicates. 


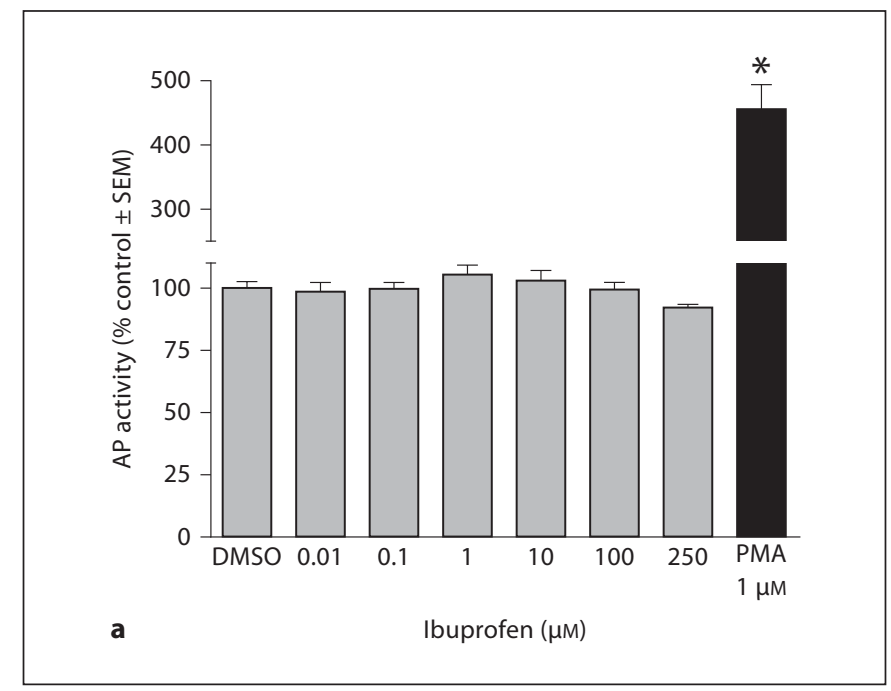

Fig. 1. NSAIDs did not modulate APP ectodomain shedding in an sAPP reporter cell line. 293 cells with a stable expression of a fusion protein consisting of AP and APP were treated for $24 \mathrm{~h}$ with ibuprofen, indomethacin or PMA, and AP activity in conditioned media was quantified with a colorimetric assay. Stimulation of the

\section{AP Assay}

AP activity was measured as described [19]. Conditioned media of 293 -EBNA cells were treated for $30 \mathrm{~min}$ at $65^{\circ} \mathrm{C}$ to heat-inactivate the endogenous AP activity. Subsequently, $20 \mu \mathrm{l}$ of medium were mixed with $200 \mu \mathrm{l}$ substrate solution (0.1 M glycine, $\mathrm{pH} 10.4$, $1 \mathrm{mM} \mathrm{Mg}_{2} \mathrm{Cl}, 1 \mathrm{mM} \mathrm{ZnCl}_{2}$ containing $1 \mathrm{mg} / \mathrm{ml}$ 4-nitrophenyl phosphate disodium salt hexahydrate), and incubated for $1 \mathrm{~h}$ at room temperature in the dark. The reaction was stopped by adding 1/5 volume $3 \mathrm{M} \mathrm{NaOH}$, and absorbance was read at $405 \mathrm{~nm}$.

Western Blot and Pulse-Chase Analysis of sAPP Secretion and Cellular APP Expression after NSAID Treatment

For analysis of endogenous sAPP secretion by Western blotting, $400 \mu \mathrm{l}$ of conditioned cell culture media were mixed with $1 \times$ complete protease inhibitor cocktail $(1 \times$ PI; Roche Diagnostics $\mathrm{GmbH}$, Mannheim, Germany). Subsequently, supernatants were concentrated by centrifugal filters (Microcon YM-50, Millipore, Schwalbach, Germany) and adjusted with NP40 buffer (1\% NP40, $50 \mathrm{~mm}$ Tris, $\mathrm{pH} 8.0,150 \mathrm{mM} \mathrm{NaCl}, 1 \times \mathrm{PI})$ to a volume of $50 \mu \mathrm{l}$. Equal volumes of concentrates were resolved on $4-12 \%$ BisTris gels (Invitrogen), and total sAPP and sAPP- $\alpha$ levels were determined by Western blotting with MAbs IG7/5A3 or 26D6. In the experiments with primary chicken neurons, duplicates from each drug concentration were pooled prior to Western blot analysis, and total sAPP levels were determined with polyclonal antiserum 863. Chemiluminescence was recorded with an LAS 3000 ECL camera system and quantified with the densitometry software AIDA (Fuji Photo Film GmbH, Düsseldorf, Germany). For analysis of cellular APP expression, cells were lysed in NP40 buffer, and equal protein amounts were separated on $4-12 \%$ Bis-Tris gels and analyzed by Western blotting with polyclonal antibody CT-15.

NSAIDs and Ectodomain Shedding of the APP

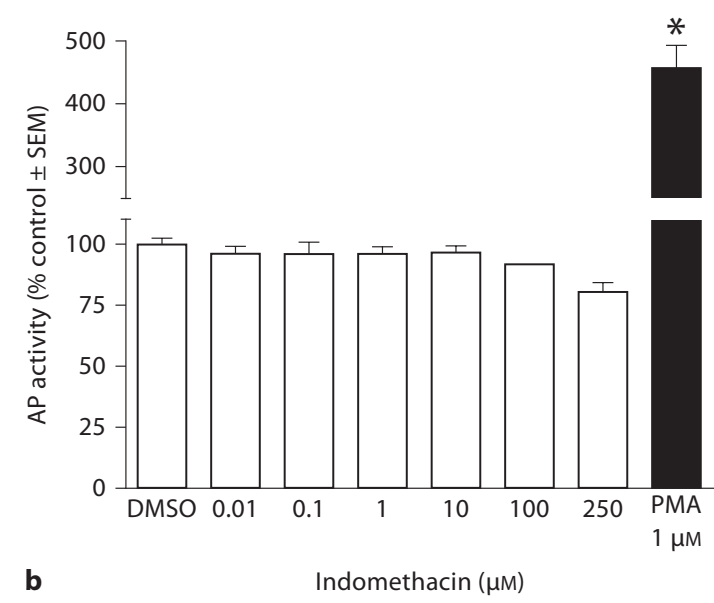

$\alpha$-secretase pathway with PMA induced a 4 -fold increase in AP activity. In contrast, neither ibuprofen (a) nor indomethacin (b) treatment had any effect on SAPP release and AP activity: $\mathrm{n}=4$, one-way ANOVA, * $\mathrm{p}<0.01$ Dunnett's post hoc tests.

For pulse-chase analysis of total sAPP release and cellular APP levels, PC12 cells were pretreated for $24 \mathrm{~h}$ with NSAIDs or DMSO vehicle in DMEM with 0.5\% FBS. Cells were starved for $30 \mathrm{~min}$ in DMEM without methionine, metabolically labeled for $20 \mathrm{~min}$ with $350 \mu \mathrm{Ci}\left[{ }^{35} \mathrm{~S}\right]$-methionine, and then chased for $4 \mathrm{~h}$ in cold DMEM with $0.5 \%$ FBS in the presence of NSAIDs, PMA or DMSO vehicle. Chase media were collected and sAPP was immunoprecipitated with MAbs IG7/5A3 and anti-mouse IgG-conjugated agarose beads (American Qualex, San Clemente, Calif., USA). Corresponding cells were lysed in NP40 buffer, and APP was immunoprecipitated with polyclonal antibody CT-15 and rec-protein A-sepharose 4B (Invitrogen). Immunoprecipitates were resolved on $4-12 \%$ Bis-Tris gels and analyzed by phosphor imaging.

\section{Statistical Analysis}

Dose-response experiments were repeated at least 3 times, and results were normalized to DMSO control condition and analyzed by one-way ANOVA with Dunnett's post hoc tests and drug concentration as categorical variable. Statistics were performed using GraphPad Prism software (GraphPad Software, San Diego, Calif., USA).

\section{Results and Discussion}

In previous studies using APP-transfected $\mathrm{CHO}$ cells, we demonstrated that the NSAID sulindac sulfide did not affect levels of total sAPP, sAPP- $\alpha$, APP-CTFs or APP holoprotein expression by Western blotting [15]. Similar results have been reported with other NSAIDs including 

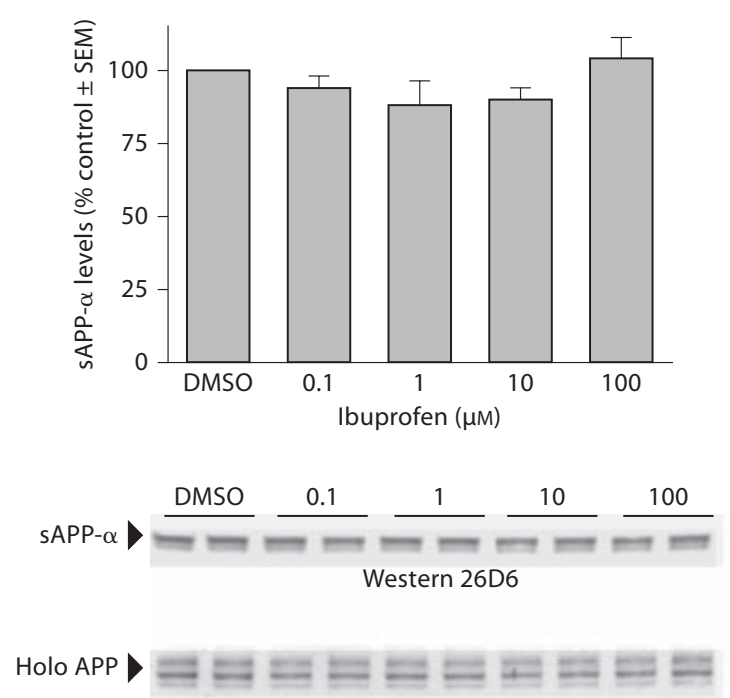

a

Western CT-15
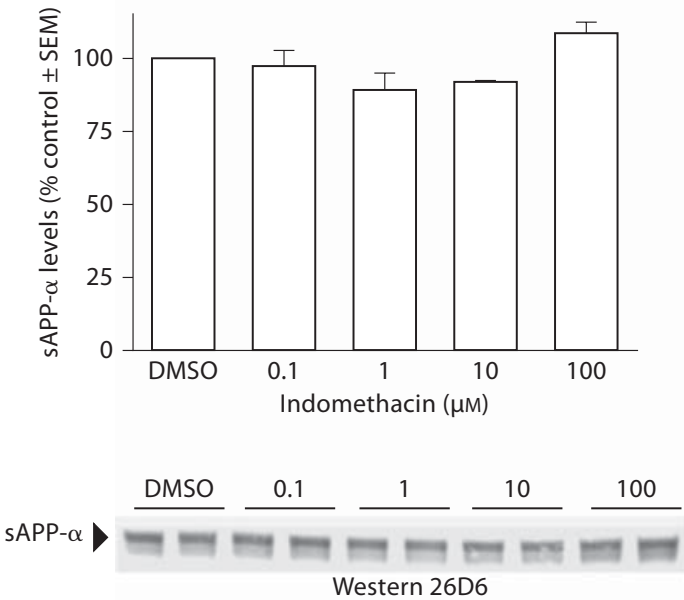

HoloAPP b

Western CT-15
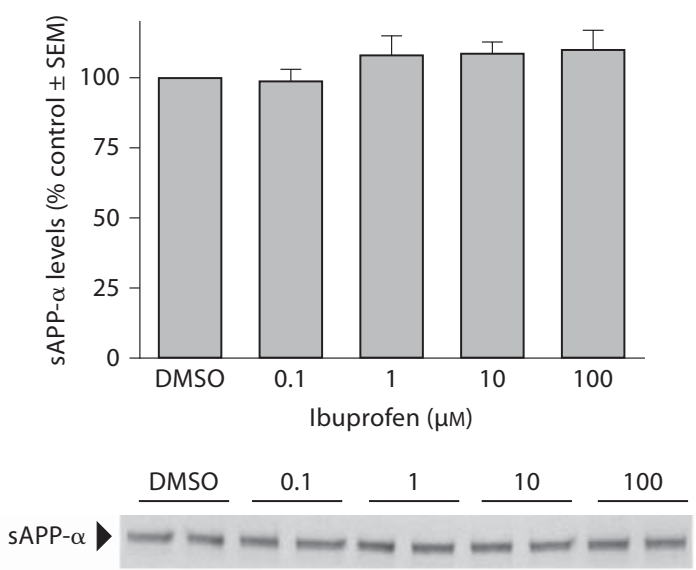

Western 26D6

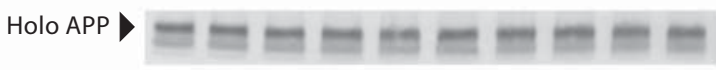

C

Western CT-15
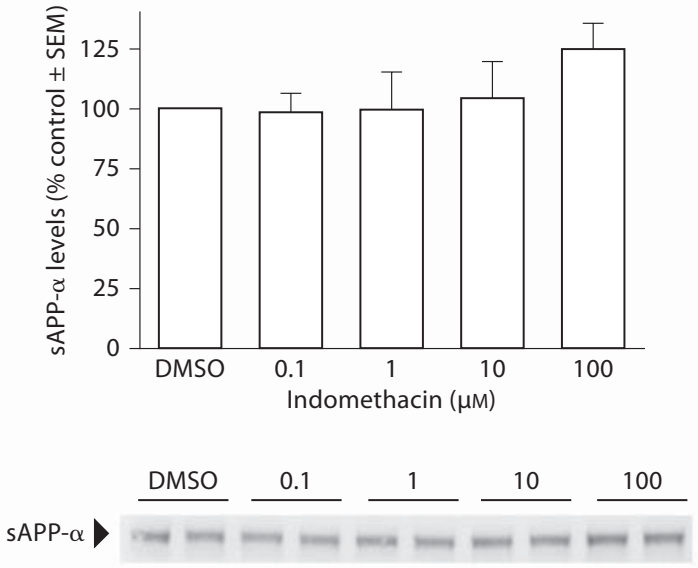

Western 26D6

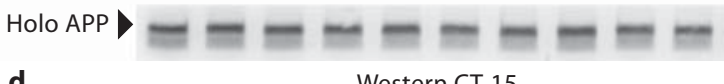

d

Western CT-15
Fig. 2. NSAIDs did not stimulate $s A P P-\alpha$ release from endogenous APP in neuronal cell lines. Human SH-SY5Y cells $(\mathbf{a}, \mathbf{b})$ or rat PC12 cells (c, d) were treated for $24 \mathrm{~h}$ with ibuprofen or indomethacin, and sAPP- $\alpha$ release in conditioned media was detected by Western blotting with MAb 26D6 against amino acid residues 1-12 of the human $A \beta$ sequence. In corresponding cell lysates, APP holoprotein levels were analyzed with antibody CT-15 against the C-terminal 15 amino acid residues of human APP. Ibuprofen $(\mathbf{a}, \mathbf{c})$ and indomethacin $(\mathbf{b}, \mathbf{d})$ treatments exerted no significant effects on sAPP- $\alpha$ release or cellular APP expression levels. For quantification of sAPP- $\alpha$ levels, results from 3 independent experiments carried out in duplicate were averaged and analyzed by one-way ANOVA. Representative Western blotting results for sAPP- $\alpha$ and cellular APP are shown below. 


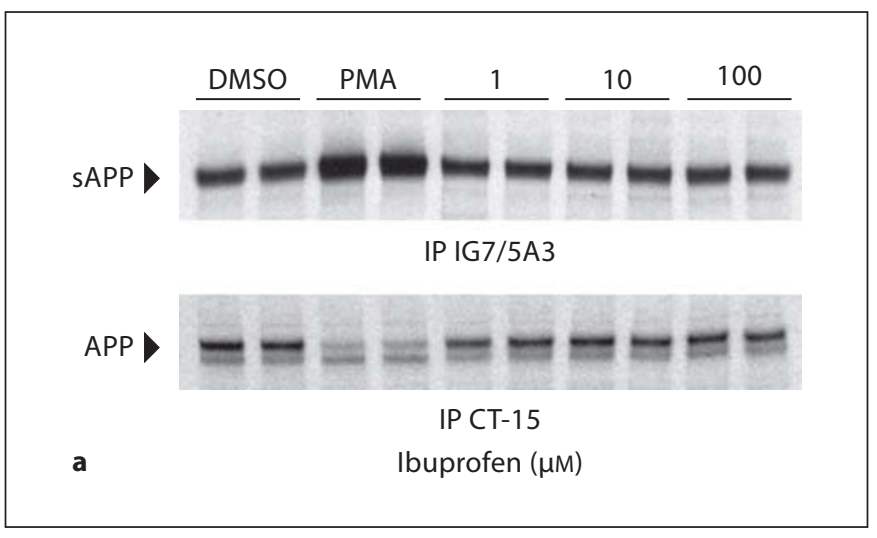

Fig. 3. Pulse-chase analysis of sAPP release after NSAID treatment in PC12 cells. PC12 cells were pretreated for $24 \mathrm{~h}$ with the indicated concentrations of NSAIDs, labeled with $\left[{ }^{35} \mathrm{~S}\right]$-methionine, and chased for $4 \mathrm{~h}$ with cold medium in the presence of NSAIDs or PMA. sAPP was immunoprecipitated from conditioned media with MAbs IG7/5A3 against the APP ectodomain,

ibuprofen in APP-transfected HEK 293 and N2a cells [13, 14]. To further substantiate these findings, we treated a HEK-293-based sAPP reporter cell line with low to high concentrations $(0.01-250 \mu \mathrm{M})$ of the NSAIDs ibuprofen and indomethacin. These cells stably express a fusion protein consisting of secretory AP and full-length APP, and allow precise quantification of APP ectodomain shedding by determination of AP activity in conditioned media with a simple colorimetric assay [19]. Neither ibuprofen (fig. 1a) nor indomethacin (fig. 1b) displayed any stimulating effects on APP ectodomain shedding in this assay. As a positive control, cells were treated with the phorbol ester PMA, which enhances $\alpha$-secretase-mediated cleavage of APP $[5,6]$. As previously reported [19], PMA treatment increased AP activity around 4-fold demonstrating that the shedding machinery was not saturated in this culture system (fig. 1).

Avramovich et al. [10] have reported that sustained treatment $(20 \mathrm{~h})$ of neuronal SH-SY5Y or PC12 cells with ibuprofen or indomethacin prominently stimulated generation of sAPP- $\alpha$. In this study, a bimodal effect of NSAID treatment was observed with a maximal stimulation of sAPP- $\alpha$ levels at low micromolar concentrations (0.1-10 $\mu \mathrm{M})$ and reductions in sAPP- $\alpha$ levels at higher concentrations $(100 \mu \mathrm{M})$. In addition, elevations in sAPP$\alpha$ levels after NSAID treatment were accompanied by reductions in levels of cellular APP holoprotein [10]. These experiments differed from our own and other studies in three significant ways [13-15]. First, they were performed in neuronal cell lines and it seemed possible that modula-

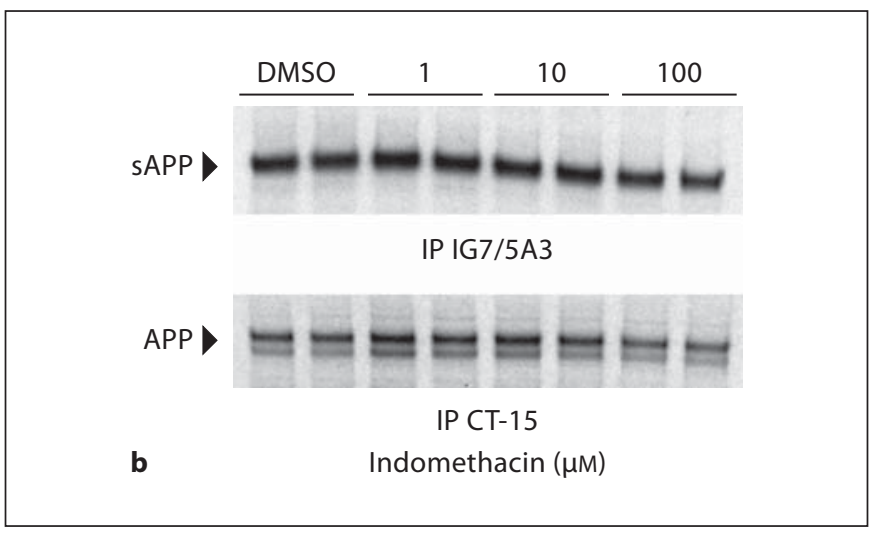

and APP holoprotein levels were analyzed in corresponding cell lysates with antibody CT-15 against the C-terminus of APP. As expected, PMA treatment increased sAPP levels and decreased mature APP holoprotein (a). However, ibuprofen (a) or indomethacin (b) treatments did not stimulate sAPP generation or lower APP holoprotein levels. tion of APP ectodomain shedding occurs only in cells of neuronal origin but not in peripheral cell lines. Second, whereas we and others used cell lines with ectopic expression of APP [13-15], this study described sAPP- $\alpha$ stimulation from endogenous APP [10]. This aspect could have provided an explanation for the divergent results, for instance if NSAIDs promoted stimulation of the endogenous APP promoter or stabilization of APP protein levels, thereby generating more substrate for $\alpha$-secretase. Third, lower NSAID concentrations were explored and found to be effective [10].

To exclude that any of these possibilities might have prevented us from detecting stimulating effects of NSAIDs on APP ectodomain shedding, we attempted to reproduce the results by Avramovich et al. [10] with interchangeable experimental approaches. SH-SY5Y or $\mathrm{PC} 12$ cells were treated under low-serum conditions with 0.1-100 $\mu \mathrm{M}$ of ibuprofen or indomethacin, and sAPP- $\alpha$ and total sAPP levels in conditioned media were quantified by Western blotting. Detection of sAPP- $\alpha$ with MAb 26D6 did not reveal modulatory effects of ibuprofen or indomethacin in SH-SY5Y (fig. 2a, b) or PC12 cells (fig. 2c, d) over the entire concentration range. Similar negative results were obtained when total sAPP levels in PC12 cells were detected with MAbs IG7/5A3 directed against $\mathrm{N}$-terminal epitopes in the APP ectodomain (data not shown). We also analyzed corresponding cell lysates with polyclonal antibody CT- 15 against the C-terminus of APP. No changes in steady-state levels of APP were observed after NSAID treatment (fig. 2). 

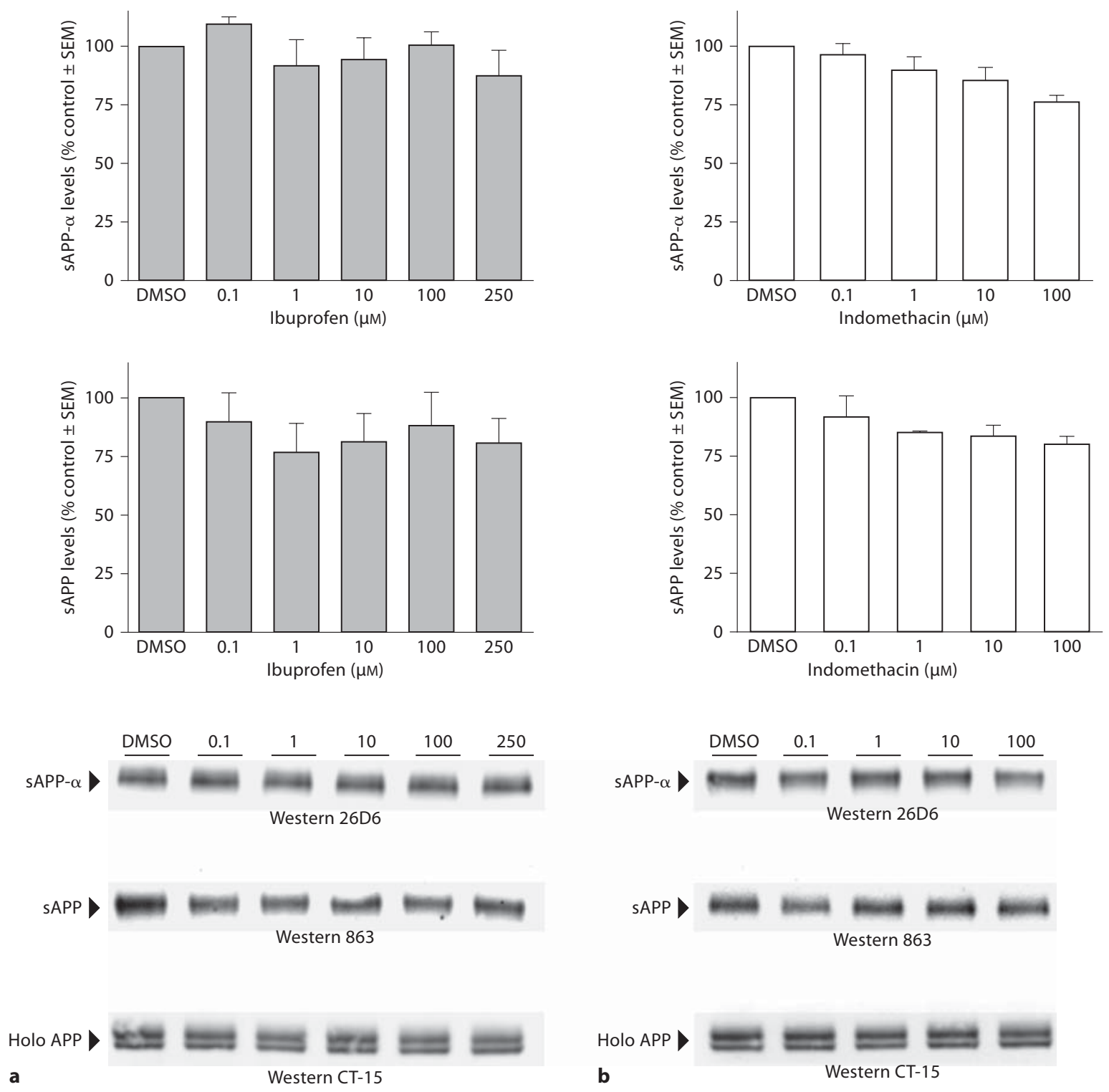

Holo APP

b

Western CT-15

Fig. 4. sAPP release after NSAID treatment in primary neuronal cultures. Primary telencephalic chicken neurons were treated after 5 days in culture for $24 \mathrm{~h}$ with ibuprofen or indomethacin. sAPP- $\alpha$ and total sAPP levels were analyzed in conditioned media with the sAPP- $\alpha$-specific MAb 26D6 or the polyclonal antiserum 863 raised against the mid-region of APP. APP holoprotein levels in corresponding cell lysates were detected with antibody CT-15 against the C-terminus of APP. In accordance with the results in permanent cell lines, neither ibuprofen (a) nor indomethacin (b) treatment resulted in significant changes in sAPP- $\alpha$, total sAPP or cellular APP levels. For quantification of sAPP- $\alpha$ and total sAPP levels, results from 3 independent experiments were averaged and analyzed by one-way ANOVA. Representative Western blotting results for SAPP- $\alpha$, total sAPP and cellular APP are shown below. 
To further confirm these results, total sAPP levels after NSAID treatment were examined in a pulse-chase paradigm. PC12 cells were pretreated for $24 \mathrm{~h}$ with the indicated concentrations of ibuprofen and indomethacin, labeled for $20 \mathrm{~min}$ with $\left[{ }^{35} \mathrm{~S}\right]$-methionine containing medium, and subsequently chased for $4 \mathrm{~h}$ with cold medium in the presence of NSAIDs or PMA. sAPP was immunoprecipitated from conditioned media with MAbs IG7/ 5A3, and APP holoprotein levels were analyzed in corresponding cell lysates with antibody CT-15. As expected, PMA treatment increased sAPP levels and decreased mature cell-associated APP holoprotein (fig. 3a). However, ibuprofen (fig. 3a) or indomethacin (fig. 3b) treatment failed to stimulate sAPP generation or lower cellular APP holoprotein.

Finally, we intended to corroborate our findings in a primary neuronal culture system. For these experiments, primary telencephalic chicken neuronal cultures were chosen because of the identity between the chicken $A \beta$ sequence and the human sequence [20]. For that reason, detection of endogenous SAPP- $\alpha$ species in chicken neurons is feasible with available human-specific $A \beta$ antibodies. Neurons were treated after 5 days in culture with $0.1-250 \mu \mathrm{M}$ of ibuprofen or indomethacin, and conditioned media and corresponding cell lysates were analyzed by Western blotting as described above. In agreement with our results in permanent cell lines, neither ibuprofen (fig. 4a) nor indomethacin (fig. 4b) treatment resulted in significant changes in SAPP- $\alpha$, total sAPP, or cellular APP levels.

In summary, we have been unable to confirm modulation of APP ectodomain shedding with the NSAIDs ibuprofen and indomethacin. The underlying reasons for the obvious inconsistencies between our results and previous studies remain unclear $[10,11]$, but we consider it unlikely that minor experimental differences between studies could explain the divergent outcomes. Ibuprofen and indomethacin belong to the most frequently prescribed NSAIDs. Accordingly, these drugs should have made a substantial contribution to the reported inverse correlation between NSAID use and AD risk as revealed in many epidemiological studies. For example in the Rotterdam Study, a prospective study of almost 7,000 subjects, which described an $80 \%$ risk reduction for $\mathrm{AD}$ associated with NSAID use, ibuprofen and indomethacin accounted for about $26 \%$ of all NSAID prescriptions [21]. Furthermore, in clinical trials, indomethacin was the only NSAID reported to provide slowing of symptom progression in $\mathrm{AD}$ patients [22]. Consequently, we believe that our comprehensive studies in APP-transfected and nontransfected cell culture systems of neuronal and nonneuronal origin provide compelling evidence that chronic stimulation of sAPP release is not a relevant activity of these compounds and not an alternative mechanism of action of NSAID in AD.

\section{Acknowledgements}

We wish to thank Dr. Edward Koo (UC San Diego) for providing antibodies. Research by S.L., E.C., J.N. and S.W. is generously supported by the Emmy Noether-program of the Deutsche Forschungsgemeinschaft (DFG, WE 2561/1-3). S.F.L. is supported by SFB596 of the DFG. We further would like to thank Dr. Guido Reifenberger (University of Düsseldorf) for encouragement and support.

\section{References}

1 McGeer PL, McGeer EG: NSAIDs and Alzheimer disease: epidemiological, animal model and clinical studies. Neurobiol Aging 2007;28:639-647.

2 Leuchtenberger S, Beher D, Weggen S: Selective modulation of Abeta42 production in Alzheimer's disease: non-steroidal anti-inflammatory drugs (NSAIDs) and beyond. Curr Pharm Des 2006;12:4337-4355.

3 Wilquet V, De Strooper B: Amyloid-beta precursor protein processing in neurodegeneration. Curr Opin Neurobiol 2004;14:582588 .
4 Kojro E, Fahrenholz F: The non-amyloidogenic pathway: structure and function of alpha-secretases. Subcell Biochem 2005;38: 105-127.

5 Mills J, Reiner PB: Regulation of amyloid precursor protein cleavage. J Neurochem 1999;72:443-460.

6 Allinson TM, Parkin ET, Turner AJ, Hooper NM: ADAMs family members as amyloid precursor protein alpha-secretases. J Neurosci Res 2003;74:342-352.

7 Warner TD, Mitchell JA: Cyclooxygenases: new forms, new inhibitors, and lessons from the clinic. FASEB J 2004;18:790-804.
8 Baron JA, Sandler RS: Nonsteroidal anti-inflammatory drugs and cancer prevention. Annu Rev Med 2000;51:511-523.

9 Nishizuka Y: Protein kinase C and lipid signaling for sustained cellular responses. FASEB J 1995;9:484-496.

10 Avramovich Y, Amit T, Youdim MB: Nonsteroidal anti-inflammatory drugs stimulate secretion of non-amyloidogenic precursor protein. J Biol Chem 2002;277:31466-31473.

11 Kinouchi T, Ono Y, Sorimachi H, Ishiura S, Suzuki K: Arachidonate metabolites affect the secretion of an $\mathrm{N}$-terminal fragment of Alzheimer's disease amyloid precursor protein. Biochem Biophys Res Commun 1995; 209:841-849. 
12 Cho HW, Kim JH, Choi S, Kim HJ: Phospholipase $A_{2}$ is involved in muscarinic receptormediated sAPPalpha release independently of cyclooxygenase or lypoxygenase activity in SH-SY5Y cells. Neurosci Lett 2006;397: 214-218.

13 Gasparini L, Rusconi L, Xu H, Del Soldato P, Ongini E: Modulation of beta-amyloid metabolism by non-steroidal anti-inflammatory drugs in neuronal cell cultures. J Neurochem 2004;88:337-348.

14 Morihara T, Chu T, Ubeda O, Beech W, Cole GM: Selective inhibition of Abeta 42 production by NSAID R-enantiomers. J Neurochem 2002;83:1009-1012.

15 Weggen S, Eriksen JL, Das P, Sagi SA, Wang R, Pietrzik CU, Findlay KA, Smith TE, Murphy MP, Bulter T, Kang DE, Marquez-Sterling $\mathrm{N}$, Golde TE, Koo EH: A subset of NSAIDs lower amyloidogenic Abeta42 independently of cyclooxygenase activity. Nature 2001;414:212-216.
16 Dash PK, Moore AN: Enhanced processing of APP induced by IL-1 beta can be reduced by indomethacin and nordihydroguaiaretic acid. Biochem Biophys Res Commun 1995; 208:542-548.

17 Skovronsky DM, Lee VM, Pratico D: Amyloid precursor protein and amyloid beta peptide in human platelets. Role of cyclooxygenase and protein kinase C. J Biol Chem 2001; 276:17036-17043.

18 Leuchtenberger S, Kummer MP, Kukar T, Czirr E, Teusch N, Sagi SA, Berdeaux R, Pietrzik CU, Ladd TB, Golde TE, Koo EH, Weggen S: Inhibitors of Rho-kinase modulate amyloid-beta (Abeta) secretion but lack selectivity for Abeta42. J Neurochem 2006; 96:355-365.

19 Schobel S, Neumann S, Seed B, Lichtenthaler SF: Expression cloning screen for modifiers of amyloid precursor protein shedding. Int J Dev Neurosci 2006;24:141-148.
20 Esselmann H, Maler JM, Kunz N, Otto M, Paul S, Lewczuk P, Ruether E, Kornhuber J, Wiltfang J: Lithium decreases secretion of Abeta1-42 and C-truncated species Abeta1$37 / 38 / 39 / 40$ in chicken telencephalic cultures but specifically increases intracellular Abeta1-38. Neurodegener Dis 2004;1:236241.

21 in t'Veld BA, Ruitenberg A, Hofman A, Launer LJ, van Duijn CM, Stijnen T, Breteler MM, Stricker BH: Nonsteroidal antiinflammatory drugs and the risk of Alzheimer's disease. N Engl J Med 2001;345:1515-1521.

22 Rogers J, Kirby LC, Hempelman SR, Berry DL, McGeer PL, Kaszniak AW, Zalinski J, Cofield M, Mansukhani L, Willson P, et al: Clinical trial of indomethacin in Alzheimer's disease. Neurology 1993;43:16091611. 